\title{
THE USE OF KNOWLEDGE FOR TECHNOLOGICAL INNOVATION WITHIN DIVERSIFIED FIRMS
}

\author{
DOUGLAS J. MILLER \\ University of Illinois at Urbana-Champaign \\ MICHAEL J. FERN \\ University of Victoria \\ LAURA B. CARDINAL \\ Tulane University
}

\begin{abstract}
We propose that searching for and transferring knowledge across divisions in a diversified firm can cultivate innovation. Using a sample of 211,636 patents from 1,644 companies during the period 1985-96, we find that the use of interdivisional knowledge positively affects the impact of an invention on subsequent technological developments. Furthermore, the positive effect of the use of interdivisional knowledge on the impact of an invention is stronger than the effect of using knowledge from within divisional boundaries or from outside firm boundaries. Our empirical findings have significant implications for the management of knowledge in diversified firms.
\end{abstract}

As to moving ideas around diverse businesses that don't have a lot in common, General Electric does this because it has to. If it doesn't, then it is just a holding company. ... A breakthrough in GE's Medical Systems business, with relatively little modification, led to a method by which an aircraft engine can transmit continuous information about blade speed, engine heat and other relevant data about its in-flight performance well in advance of any possible safety situation. This innovation, in turn, catalyzed an important new development with respect to a self-monitoring system for use with heart pacemakers. I could cite any number of other examples having to do with sharing methods of selling, sourcing techniques, procedures for improved storage and security of data and so on.

\section{-Steve Kerr, vice president of Corporate Leadership Development and chief learning officer, General Electric Corporation, 1997}

Throughout a broad set of industries, innovation underlies the ability of firms to sustain competitive advantage. As Brown and Eisenhardt suggested, "[Innovation] is among the essential processes for success, survival, and renewal of organizations, particularly for firms in either fast-paced or competitive markets" (1995: 344). Scholars explain that innovation requires the mastery of two divergent tasks (March, 1991; Nerkar \& Roberts, 2004). On the one hand, a firm must center its attention on a bounded set of techniques to cultivate valuable and commercially viable products; the task here is local search, or exploitation (Leonard-Barton, 1992; March, 1991). On the other hand, a firm must continually acquire a diverse and novel body of knowledge that will serve as the seed for future technological developments; the firm's task here is distant search, or exploration (March, 1991; Nelson \& Winter, 1982). Although firms are generally adept at local search, distant search is challenging (Henderson \& Clark, 1990; Tushman \& Anderson, 1986). A firm's accumulated capabilities delimit the scope of search and the capacity to comprehend and apply new knowledge (Cohen \& Levinthal, 1990; Nelson \& Winter, 1982). Further, in carrying out distant search, firms must often span organizational boundaries, yet knowledge is especially difficult to identify and acquire through market mechanisms (Teece, 1980; von Hippel, 1994).

Scholars point to three external market mechanisms that firms employ to manage the difficulties of distant search: alliances (e.g., Grant, 1996; Rosenkopf \& Almeida, 2003), inventor mobility (e.g., Almeida \& Kogut, 1999; Argote \& Ingram, 2000; Song, Almeida, \& Wu, 2003), and horizontal (i.e., within-industry) acquisitions (e.g., Ahuja \& Katila, 2001; Capron, Dussauge, \& Mitchell, 1998). The use of interdivisional knowledge may represent a viable complement to alliances, inventor mobility, or horizontal acquisitions and may have significant influence on a firm's ability to conceive and codify valuable technological discoveries. As Tsai remarked, "Knowledge transfer among organizational units provides opportunities for mutual learning and interunit cooperation that stimulate 
the creation of new knowledge and, at the same time, contribute to organizational units' ability to innovate" (2001: 996). Despite the arguments of researchers stressing that knowledge flows better within firm boundaries than across them (e.g., Fern \& Cardinal, 2003; Grant, 1996; Liebeskind, 1996; Szulanski, 1996; Teece, 1980; Williamson, 1981), understanding of interdivisional knowledge flows remains incomplete (Argyres, 1996; Argyres \& Silverman, 2004; Gupta \& Govindarajan, 2000; Hansen, 2002). Accordingly, the purpose of this study was to gain further insight regarding the implications of interdivisional knowledge flows by exploring the relationship between the search and transfer of interdivisional knowledge and technological innovation.

\section{SOURCING KNOWLEDGE FOR INNOVATION}

Scholars stress the importance of intangible assets for attaining superior performance and a sustainable competitive advantage (Barney, 1991; Grant, 1996). Among intangible assets, knowledge is arguably the most important resource a firm controls (Liebeskind, 1996). Of particular relevance for this research, scholars suggest that knowledge is one of the principal inputs into the innovation process (Rosenkopf \& Almeida, 2003).

\section{The Use of Local and Distant Knowledge}

This research investigates how the use of distant knowledge contributes to innovation. We employ the term "use of knowledge" to encompass the search and transfer of technology during an innovation process. The identified and transferred technology might be used as a foundation for development or it might be used for other purposes, such as distinguishing gaps within the extant technology landscape. Viewing innovation as "new combinations" of existing technology (Schumpeter, 1947), we distinguish between local and distant combinations. Local combinations arise when an inventing firm recombines knowledge elements from a familiar space or refines an existing knowledge combination. In contrast, distant combinations comprise far-flung knowledge elements (March, 1991). The bridging of distant knowledge elements can be arduous and costly, and it may never produce a viable combination. Furthermore, viable combinations may have little or no commercial value. Despite these perils, sourcing distant knowledge is fundamental to reinvigorating existing knowledge and developing new capabilities (Gavetti \& Levinthal, 2000; March, 1991). New combinations of distant knowledge may produce path-breaking innovations
(Fleming, 2001; Galunic \& Rodan, 1998; Nelson \& Winter, 1982; Nerkar \& Roberts, 2004; Schumpeter, 1947) or enable the transition from an entrenched set of techniques and designs to a new technological paradigm (e.g., Abernathy \& Utterback, 1978).

\section{Knowledge Exploration across Organizational Boundaries}

Generally, an organization is not sufficiently equipped to execute the efforts that lead to these distant combinations (Pisano, 1990). The requisite knowledge might span technological domains, geographic distance, epistemic communities, languages, legal regimes, time, and other dimensions of distance. To execute distant combinations, a firm must often identify distant knowledge elements from outside its boundaries and transfer them inside its boundaries, to the locus of its problemsolving activity (Tushman, 1977; von Hippel, 1994). To seek out these elements, firm members may attend conferences, browse patents, read trade journals, or reverse-engineer competing products. Such activities, however, may be insufficient to bridge the gap between simply identifying distant knowledge elements and actually applying them in creative ways within firm boundaries. Innovating firms may encounter a number of critical barriers.

At the individual level, barriers to the identification and transfer of knowledge across organizational boundaries emerge from individuals' cognitive constraints (March \& Simon, 1958; Simon, 1962). To cope with uncertainties and a myriad of stimuli, individuals employ knowledge structures (i.e., schemata) to aid in information processing and decision making (Walsh, 1995). Knowledge structures may limit a person's ability to properly appraise the opportunities and limitations of his or her existing knowledge, gain awareness of knowledge that resides in the environment, or readily transfer that knowledge for use in decision making.

At the organizational level, constraints to the identification and transfer of knowledge across boundaries emerge from the shared routines that evolve from an organization's unique history (March \& Simon, 1958; Nelson \& Winter, 1982; Stuart \& Podolny, 1996). Over time, organizations develop specific communication channels and information filters that constrain the range of the knowledge that the firms explore (Henderson \& Clark, 1990). Even if a firm decides to search outside this limited range, knowledge that substantially deviates from the firm's core technical abilities is often difficult for its members to comprehend and subsequently apply (Cohen \& Levinthal, 1990: Nelson \& Winter, 1982; Tushman \& Anderson, 1986). 
Certain characteristics of knowledge exacerbate these constraints on the search for and transfer of knowledge over organizational boundaries. For instance, a preponderance of knowledge often remains in tacit form (Polanyi \& Walshe, 1966). The tacit nature of some knowledge hampers the owner's ability to identify it as a potential component for exchange, prevents other organizations from becoming aware of its presence, and also hampers transmission of the knowledge once it is identified. Transmission is hindered because tacit knowledge is often imperfectly understood (i.e., causally ambiguous), which impedes the task of codification (Szulanksi, 1996). Second, since knowledge is often a source of competitive advantage, managers actively work to keep it secret or protected to preclude its imitation by competitors (Liebeskind, 1996). The difficulty of buying and selling proprietary knowledge stems from the simple irony that the value of knowledge can only be determined after it has been shared with a buyer, but then the buyer has acquired the knowledge at no cost (Arrow, 1962; Teece, 1986). Even if the aforementioned barriers can be overcome, individuals may be reluctant to source knowledge from outside the boundaries of their own firm because the knowledge is unproven within the organization (Szulanski, 1996).

Firms can compensate for some of these difficulties associated with knowledge transfer by relying on various mechanisms, including interorganizational alliances (Grant, 1996; Hamel, 1991; Liebeskind, Oliver, Zucker, \& Brewer, 1996; Mowery, Oxley, \& Silverman, 1996; Rosenkopf \& Almeida, 2003), the employment of new inventors (Almeida \& Kogut, 1999; Argote \& Ingram, 2000; Rosenkopf \& Almeida, 2003; Song et al., 2003), and the acquisition of other firms (and, hence, their employees' embedded knowledge) (Ahuja \& Katila, 2001; Capron et al., 1998; Karim \& Mitchell, 2000). As noted in the literature, however, these compensating mechanisms have significant pitfalls (Chi, 1994; Coff, 1999; Hitt, Hoskisson, Ireland, \& Harrison, 1991; Jemison \& Sitkin, 1986; Nagarajan \& Mitchell, 1998). We propose that, to complement these mechanisms, a diversified firm can use distant knowledge by identifying and transferring knowledge across divisions or units that lie inside its broad organizational boundaries.

\section{Knowledge Exploration within Organizational Boundaries}

In this section, we suggest that because technological diversity and product-market diversification are codetermined, some firms can effectively source a breadth of knowledge- even from distant technological domains-within their own broad boundaries.

Organizational boundaries. The concept of organizational boundaries is fundamental to the study and management of organizations and intertwined with the concepts of divisionalization, diversification, and outsourcing. Historically, research on organizational boundaries has been dominated by applying an efficiency perspective, built on transaction cost economics, to explain make-or-buy decisions (Argyres, 1996; Mota \& de Castro, 2004; Williamson, 1981). Managers make vertical boundary decisions about make-or-buy decisions when they are concerned with the division of labor and the value chain (Takeishi, 2001). Managers also expand their organization's horizontal boundaries when resources are leveraged and extended beyond the organization's core business to include new products and markets. We can also differentiate between internal and external organizational boundaries (Takeishi, 2001), whereby managers choose to perform activities in-house or decide to outsource some functions to other organizations (Brusoni, Prencipe, \& Pavitt, 2001).

Research recently has begun to move beyond transaction cost conceptions of boundaries and efficiency to a broader view of organizational boundaries. We can consider organizational identity and the rules of inclusion, the garnering and allocation of resources and organizational growth, and the scope of influence and industry power (Santos \& Eisenhardt, 2005). Each of these contemporary conceptions represents distinctions related to how organizations relate to their environments.

When one thinks of diversification in organizational boundary terms, one is essentially conceptualizing diversification as capturing the distinct resources and capabilities of different divisions and the respective product-market environments. In keeping with both Santos and Eisenhardt's (2005) competence view of boundaries and research addressing both transaction costs and firm capabilities in relation to external boundary decisions (e.g., Leiblein \& Miller, 2003), we highlight the importance of knowledge in setting internal boundaries in relation to different product-market domains.

Intrafirm technological diversity. Some firms operate using a broader range of knowledge than do other firms; that is, firms differ in their technological diversity (e.g., Pavitt, Robson, \& Townsend, 1989). Foremost, in many industries, the knowhow required to manufacture a product spans multiple domains. For instance, innovation in industrial machinery often requires electrical, mechanical, and software engineering (Argyres, 1996). 
A firm may also require knowledge of multiple technologies to work effectively with its network of suppliers (Brusoni et al., 2001), especially when the end product is comprised of a variety of subcomponents (e.g., personal computers). Further, diversification strategies can yield technological diversity within a single firm. The research on strategy identifies the benefits of diversification, especially related diversification (Markides \& Williamson, 1994; Palich, Cardinal, \& Miller, 2000; Robins \& Wiersema, 1995). The derivation of new products and services from existing knowledge often requires combination with other knowledge, so related-diversified firms expand their breadth of knowledge over time (Chang, 1996; Miller, 2004; Pavitt et al., 1989). Furthermore, firms pursuing unrelated diversification tend to have divisions with divergent products and technologies. These seemingly unrelated subsidiaries may stumble into technological synergies over time.

Firm divisionalization. Generally, behavioral theorists argue for integrating highly interdependent knowledge components (Fleming \& Sorenson, 2004) used in design or production within a firm's hierarchy (Nayyar \& Kazanjian, 1993; Nickerson \& Zenger, 2004; Simon, 1962). Within a single organization, identification and transfer of knowledge is greatly simplified because employees learn firmspecific communication codes that facilitate the exchange of knowledge necessary to execute job tasks (Kogut \& Zander, 1992; Tushman, 1977). Moreover, the hierarchy establishes interfaces between functional teams, simplifying coordination and promoting flexibility through the possibility of realigning portions of the firm's modular structure (Simon, 1962). Williamson's claims about the efficiency of the multidivisional firm arise directly from the communication and coordination benefits of hierarchy in information processing (see Williamson, 1985: 281-283). However, Williamson further argued that when divisional boundaries separate groups of people with different knowledge from each other, the potential for opportunism is great. In fact, he defined opportunism as essentially the incomplete or distorted disclosure of information with the intention of benefiting oneself in a situation of information asymmetry (Williamson, 1975, 1985). Within the M-form structure, the general office of a firm needs to address both information-processing concerns and opportunism by establishing the right internal boundaries.

Following the theory of transaction cost economics, Argyres (1996) argued that the diversity of R\&D efforts has a predictable relationship with organizational structure. A firm exploring new combinations of knowledge will have fewer divisions than a firm that is not exploring as extensively, so as to lessen the difficulties involved in transferring knowledge over division boundaries-a process subject to some of the same challenges as extraorganizational search. Certainly, centralized R\&D can generate technologies of greater impact (Argyres \& Silverman, 2004) and can service dispersed divisions while minimizing battles over R\&D allocations (Cardinal \& Opler, 1995).

However, although exploration through coordinating R\&D may push managers to dissolve internal barriers, the drive to exploit existing technology explains why divisions exist in the first place. Firms achieve exploitation through specialization-dividing themselves into various units to focus effort on specific product and geographic markets. The presence of divisionalization may also indicate that complementary assets are needed to bring products to market. For instance, firms often establish geographic divisions to colocate different domains of relevant knowledge (e.g., geographic, product-market, and technological know-how) (Nayyar \& Kazanjian, 1993; Nerkar \& Roberts, 2004) as well as to create the right incentive system for employees closer to their respective customers (Markides \& Williamson, 1994). Furthermore, divisionalization might emerge from acquisition activity. When an acquisition is intended to give access to a particular capability, it is usually best to allow the new subsidiary to remain somewhat intact; otherwise the capability may be lost before the acquirer can exploit it. Key employees of the acquired division may refuse to take part in centralized R\&D or otherwise join knowledge-sharing efforts (Cardinal \& Hatfield, 2000).

Thus, we believe diversified firms develop distinct bodies of knowledge through the planned or emergent development of divisions. Managers are not willing to completely eliminate these internal boundaries through centralization, lest their firm lose the ability to exploit existing knowledge and give appropriate incentives to employees working in distinct markets (Williamson, 1985). When the time comes to pursue new combinations of knowledge, a research team can use some of the benefits of the firm's hierarchy to access knowledge in other divisions and may well find that this knowledge is a good complement to the team's own.

\section{Hypotheses}

In our hypotheses, we propose that the use of knowledge from other divisions has a greater positive effect on innovativeness than the use of knowledge from the same division or from outside organizational boundaries. Rather than focusing on an 
organization's overall innovativeness, which may be difficult to define for firms participating in multiple industries and technological domains, we consider whether the source of knowledge affects innovativeness as exhibited through the impact of a particular invention-that is, the focal invention's relevance to subsequent inventions developed by other organizations (e.g., Argyres \& Silverman, 2004; Fleming \& Sorenson, 2004; Gittelman \& Kogut, 2003; Rosenkopf \& Nerkar, 2001). When other companies react to an invention by building upon it, it indicates that the invention has value in a product-market. Similarly, in academic research, authors frequently cite prior works, and the count of these citations is routinely used to evaluate the impact of cited papers.

Intradivisional knowledge. We argue that many firms have a number of divisions pursuing independent lines of research related to different product-markets. Although divisional boundaries create a structure for specialization, these boundaries do not preclude the occasional transfer of knowledge when firms seek radical innovation through distant search. Since divisional boundaries may exist for reasons unrelated to $\mathrm{R} \& \mathrm{D}$ concerns, at times the knowledge pool of one division may be of use in the problems faced by another division. However, the unique history of each division and the potential struggle for corporate resources motivate problem solvers to seek answers first within their own intradivisional knowledge and routines. Knowledge from within the same division is more local than knowledge from another division or outside a firm, even when both sets of knowledge fall within the same technological domain.

In view of previous research (e.g., Rosenkopf \& Nerkar, 2001), we expect an invention that draws primarily from local knowledge to be less innovative than one that uses more distant knowledge, and we therefore expect the former to have less impact on subsequent technological development. An invention exploiting predominantly intradivisional knowledge is often a refinement and extension of an existing product, rather than a departure from existing techniques (i.e., a radical innovation). Therefore, we expect the use of intradivisional knowledge to have a negative relationship with the impact of an invention.

Hypothesis 1. The use of intradivisional knowledge has a negative relationship with an invention's impact.

Extraorganizational knowledge. In contrast to local knowledge, knowledge outside the boundaries of a given firm is abundant. Extraorganizational activities enable an organization to source new knowledge from both proximate and distant technological space (Tushman, 1977). Search across organizational boundaries offers the potential for new combinations of knowledge that are truly innovative. These combinations often integrate previously disparate knowledge elements and yield new products that depart from existing technological paradigms (Fleming, 2001; Schumpeter, 1947).

Organizational boundary spanning represents a viable yet challenging option for sourcing distant knowledge. Significant barriers can substantially hamper use of knowledge over organizational boundaries (Teece, 1980; Tushman, 1977). These aforementioned impediments arise from cognitive constraints (March \& Simon, 1958), opportunistic behavior (Williamson, 1981), and the attributes of knowledge (i.e., it is often tacit and proprietary) (Grant, 1996, Liebeskind, 1996; Teece, 1980). Despite the impediments to organizational boundary spanning, however, organizations have found a moderate degree of success with this activity. With the next hypothesis, we seek to confirm earlier findings (e.g., Rosenkopf \& Nerkar, 2001) for our sample of firms in multiple industries.

Hypothesis 2. The use of extraorganizational knowledge has a positive relationship with an invention's impact.

Interdivisional knowledge. We introduce the division as a relevant boundary that distinguishes the localness of knowledge. This boundary can be distinct from technological, geographic, or other dimensions of distance, although we recognize that multibusiness firms may also organize along these dimensions, as when a firm has geographic divisions. Distinct divisions, in their pursuit of opportunities in distinct product or geographic markets, likely possess disparate knowledge elements.

When two divisions possess vastly different knowledge, one group of researchers will not have the capacity to readily identify and transfer the other's useful knowledge (Cohen \& Levinthal, 1990). However, so long as underlying disciplines demonstrate some overlap, the shared communication codes and access facilitated by hierarchy ease transfer within organizational boundaries (Kogut \& Zander, 1992; Tushman, 1977). These codes may apply mostly within divisions, yet coordination can also be enhanced firmwide. Furthermore, the managerial hierarchy of a firm has the legal status and social legitimacy needed to reduce the incidence of and loss from opportunistic behavior (Liebeskind, 1996; Williamson, 1981), yielding a high level of access to the knowledge elements (Grant, 1996; Teece, 1980). Upper management can impose initial terms and renegotiations of agree- 
ments between internal parties, reducing the need for time-consuming negotiation and complex contracts. Although a firm's hierarchy may not have access to incentive schemes that match the power of the market, "knowledge employees" who share in the profits of the firm will have less motivation to sabotage cooperation through intentional misrepresentation of facts or insufficient effort. With reduced concerns about opportunistic behavior, managers and researchers can relax protections that surround proprietary knowledge elements. Once these protections are relaxed, an individual employee or group can identify and transfer knowledge through various modes of unfettered communication (Teece, 1980), from information technology systems to face-to-face exchange. Rich modes of communication, such as group meetings, colocation, lateral transfers, and internal conferences, among others, facilitate the identification and transfer of embedded, tacit knowledge (Daft \& Lengel, 1986; Grant, 1996) within an organization.

If divisions serve as relevant markers of substantial knowledge distance within a firm, the use of knowledge from across divisional boundaries should enhance the magnitude of a resulting invention's impact.

Hypothesis 3. The use of interdivisional knowledge has a positive relationship with an invention's impact.

Interdivisional versus other knowledge. It might appear as though the effect of interdivisional knowledge use on an invention's impact should fall somewhere between the effects resulting from intradivisional knowledge use and extraorganizational knowledge use. Clearly, the most distant knowledge is that from outside a firm. If greater distance leads to inventions of greater impact, then extraorganizational transfer should have the greatest effect on an invention's impact. However, two previously discussed factors suggest that it is sufficient distance, not greatest distance, that matters. First, researchers may not be able to understand and apply knowledge that is too different, even if it is identifiable and fully accessible (Cohen \& Levinthal, 1990). Second, the combinations of knowledge must be (at least potentially) relevant to an invention to warrant a firm's attention. Although many unrelated technologies can be combined, the goal is not to derive a scientific oddity, but to synthesize complementary knowledge to cultivate innovation. Knowledge that is somewhat similar to researchers' current knowledge, but is also somewhat different, is likely best. Therefore, the knowledge within a diversified firm may be sufficiently diverse that researchers choose not to pursue even more distant knowledge from outside firm boundaries; then the benefits of intraorganizational knowledge flows come into play. Researchers from one unit of the firm who access knowledge from another unit can identify and access that knowledge more quickly, with greater understanding, and with less risk of failure than if they had accessed the same knowledge from outside the boundaries of their firm. Although there are impediments to the search and transfer of knowledge within the boundaries of a firm, these impediments are exacerbated when search and transfer are attempted across organizational boundaries (Szulanski, 1996). As Szulanski noted, "Because internal transfers typically are hindered less by confidentiality and legal obstacles than external transfer, they could be faster and initially less complicated, all other things being equal" (1996: 27). Thus, all else being equal, the use of interdivisional knowledge should have a more strongly positive effect on impact than the use of extraorganizational knowledge.

Hypothesis 4. The use of interdivisional knowledge has a more strongly positive relationship with an invention's impact than the use of intradivisional or extraorganizational knowledge.

\section{METHODOLOGY}

\section{Data and Sample}

The main data for this research were obtained from the National Bureau of Economic Research Patent Citations Data File, which contains a breadth of information concerning every patent granted in the period 1969-99 (Hall, Jaffe, \& Trajtenberg, 2001). The data file lists the corporation and business unit that applied for each patent, the technological class to which each patent belongs, and the cited patents associated with each patent. We supplemented these data with additional information on the relevant patents using a database from the Micropatent Corporation. A number of previous scholars have used patent data as a proxy for innovation (see Argyres \& Silverman, 2004; Fleming \& Sorenson, 2004; Gittelman \& Kogut, 2003; Henderson \& Cockburn, 1994; Rosenkopf \& Nerkar, 2001). Previous research has used either the patent level or the firm level to test hypotheses about innovation. We desired to investigate firms in many industries, mainly because we believe the theory of distant search applies in a variety of settings. Once a study includes firms that operate in different industries, it is necessary to move to the patent level to control for differences in citation behavior between patent classes or technological domains. 
The NBER data include CUSIP $^{1}$ identifiers for $481,828(64 \%)$ of all 752,500 U.S. utility patents assigned to corporate owners (i.e., not individual inventors) between 1975 and 1996, a year chosen to allow for the observation of subsequent citations to those patents. We eliminated patents granted in years when a firm was not listed in COMPUSTAT (not publicly traded) and patents granted to financial firms or those with a primary SIC code of 99 (nonclassifiable establishments), leaving 382,991 patents. Single-business firms may transfer knowledge between locations or work teams, but the phenomenon considered in our hypotheses is use of knowledge over the boundaries of recognized divisions within a corporate structure. Interdivisional citations appeared in 7,748 (i.e., approximately 2 percent) of the patents. Because we used ten years of data to create control variables, only patents from 1985-96 were included. Also, the econometric model required the observation of at least two patents for each firm, with at least one having a nonzero value for the dependent variable. Thus, the sample for tests of hypotheses was 211,636 patents.

\section{Patent Citations}

The U.S. Patent and Trademark Office oversees the process of granting property rights to inventors for inventions that are "useful" and "novel." By law, patent applicants and their lawyers must include in applications all "prior art" of which they are aware: previous patents relating to the invention they are seeking to patent and its claims. A patent examiner judges the adequacy of these citations. "In principle, a citation of Patent $X$ by Patent $Y$ indicates that Patent $Y$ builds upon previously existing knowledge embodied in Patent $X$ "' (Song et al., 2003: 356). Also included on the front page of a patent is information on the inventor, the organization that will control the patent (the "assignee"), its geographic location, the dates of application and issuance, and the technological class to which the invention belongs. Given this rigorous and thorough process, many researchers have used patent data to trace innovation activity, particularly in the years since the data have become accessible in computerized form (e.g., Fleming, 2001; Henderson et al., 1998; Mowery et al., 1996; Rosenkopf \& Almeida, 2003).

However, since inventors, their employers, patent

\footnotetext{
${ }^{1}$ CUSIP stands for the Committee on Uniform Securities Identification Procedures. Standard \& Poor's assigns a unique identifier to a security on behalf of the American Banker's Association.
}

attorneys, and patent examiners all have input to the citation process, citations are a noisy indicator of the knowledge that inventors use in their inventions. Some citations may not indicate a direct knowledge link but may instead be included to clarify the claims of the new invention, defend against lawsuits, signal the potential application in multiple industries, or demonstrate the feasibility of the proposed invention (Jaffe, Trajtenberg, \& Fogarty, 2000). ${ }^{2}$ The theory of local search, however, applies to these citations as well. When searching for a patent to cite for these purposes, inventors and others are likely to encounter certain well-publicized patents, especially those recently granted in burgeoning fields of discovery. We relied on research that has illuminated many factors affecting citations, suggesting several control variables that we included to rule out alternative explanations for our results. Therefore, despite the limitations of patent data, we have confidence that our independent and dependent variables reflect knowledge flows between and within organizations.

\section{Measures}

Dependent variable. The dependent variable, impact, gauged the degree to which a firm's patents are subsequently cited by patents of other firms. Patents that are cited in future developments by other firms are deemed more relevant, innovative, and important than those patents that are disregarded (Albert, Avery, Narin, \& McAllister, 1991; Alcacer \& Gittelman, 2005; Gittelman \& Kogut, 2003; Rosenkopf \& Nerkar, 2001). Hall and Trajtenberg (2000) provided a review of the evidence on these "forward citations." Fleming and Sorenson wrote that a patent's number of forward citations "correlates highly with its technological importance, as measured by expert opinions, social value, and industry awards (Trajtenberg, 1990; Albert et al., 1991)" (2004: 917). Furthermore, highly cited patents lead to more economic profits than patents that are less frequently cited (Harhoff, Narin, Scherer, \& Vopel, 1999). To measure impact, we counted the total number of times a focal patent

\footnotetext{
${ }^{2}$ Since 2001, the U.S. Patent and Trademark Office has reported which backward citations originated in an inventor's application and which the patent examiner added. Generally, research using patent data has assumed that the examination process yields an unbiased attribution of inventions to prior art. However, the citations entered by examiners versus inventors or their patent attorneys have some differences (Alcacer \& Gittelman, 2004; Thompson \& Fox-Kean, 2005). We address these issues briefly in the Discussion section.
} 
was cited by subsequent patents, excluding selfcitations, over the period 1985-96.

Independent variables. To create the main independent variables, we examined a focal patent's citation pattern to determine whether the cited patents were held by the same division, another division in the same organization, or another organization. Each variable was a count of the number of intradivisional self-citations, interdivisional selfcitations, or extraorganizational citations.

Control variables. As noted above, the theory of local search implies patterns in the frequency of patent citations besides the direct flow of knowledge from one inventor to another. For example, one dimension of local search is time. When inventors combine state-of-the-art knowledge components rather than older technology, their inventions have greater impact (Rosenkopf \& Nerkar, 2001). Thus, we included a measure of the mean age of all citations made by each patent, average citation age. We also computed the variance in citation age to control for the potentially beneficial effects of combining older and newer knowledge components. ${ }^{3}$ Some cited patents were granted before data on ownership or technology domain were available in the database, but rather than exclude these citations, we counted them as other citations (Rosenkopf \& Nerkar, 2001). The importance of recency extends beyond specific cited patents-there are also "hot" areas of scientific progress to consider. If inventors are not familiar with the latest discoveries in microelectronics, they may not be able to design a toy, an appliance, or even an item of clothing that will have all the features customers want. Our assignment of each patent to a technological domain relied on the primary U.S. patent class to which it belonged, but most patents are assigned multiple secondary classes to aid future patent searches. Reference to technology classes that have recently seen high rates of patenting positively affects impact (Fleming, 2001). We counted the number of times a particular subclass was listed (discounting over time so more recent use counted more heavily) to create a measure of component familiarity (Fleming, 2001) to control for this effect.

It is also possible that inventors or patent examiners are familiar with certain key patents in each technological domain and conduct their search by looking for other patents that reference those key patents. Or inventors might try to signal the breadth of their claims by citing well-known patents from

\footnotetext{
${ }^{3}$ We are grateful to a reviewer for suggesting the variance in citation age variable.
}

other domains. ${ }^{4}$ We controlled for the possibility that citing important precursors affects forward citations by including a variable for the times previously cited - a count over the last ten years of citations from all assignees, adjusted by subtracting the annual mean. ${ }^{5}$

Besides the recent and frequent use of any particular patent or class, a greater number of secondary classes means a patent is more likely to turn up in other inventors' searches and so is more likely to be cited. Accordingly, Fleming and Sorenson (2004) found a relationship between the number of technologies being combined in a patent and the number of forward citations. We replicated their measures of the number of major classes, the number of subclasses, and a dummy variable to indicate when a patent listed only a single subclass to control for these effects.

Inventions may also be more innovative and thus have greater impact when they build on basic scientific knowledge (e.g., Fleming \& Sorensen, 2004; Gittelman \& Kogut, 2003; Henderson et al., 1998). Besides citing previous patents, each patent's front page lists references to nonpatent documents, such as articles in scientific journals that explain the fundamental workings of the relevant technology, or articles in trade journals that help establish the applicant's claim that the invention is useful. Most patents with nonpatent references cite the inventor's own scientific research (Tijssen, 2001). To control for the fact that patents linked to basic scientific research have a greater impact, we created a dummy variable for cite to scientific publication, which equaled 1 if a patent referenced any nonpatent precursor (Fleming \& Sorenson, 2004).

Regardless of whether the knowledge components of an invention draw on prior patents or other publications, innovation depends partly on the science underlying a technology. Even if an inventor does not understand or directly use the basic science, it still creates a map that facilitates search behavior. In particular, distinctions between areas of scientific discovery affect modularity in design. For example, computer hardware and software arose as complementary parts of the same system, generally produced by different firms, because the knowledge bases needed to create the two components were substantially different. Since truly in-

\footnotetext{
4 Thanks to a reviewer for suggesting this signaling hypothesis.

${ }^{5}$ Patent citation rates vary from year to year (Hall et al., 2001). We included year dummy variables in all models but adjusted this control variable as an extra precaution.
} 
novative ideas are new combinations of knowledge components, following the easy path of improving only one part of a "decomposable" (Simon, 1962) system should have a lower payoff than creating a new, integrated system. We adopted Fleming and Sorenson's (2004) measure of coupling to indicate "the degree to which an invention's components have been previously combined ... [because] combining some pieces which interact sensitively with each other proves more difficult than connecting relatively independent chunks of knowledge" (Fleming \& Sorenson, 2004: 916). The coupling variable and its squared term were also interacted with the measure of citation to a scientific publication to parallel the earlier research. ${ }^{6}$

Our focus on multibusiness firms in the broad economy suggests additional controls. We added the logarithm of firm assets (in millions of dollars) to control for the possibility that market power, economies of scale in $\mathrm{R} \& \mathrm{D}$, or similar factors play a role in how patents are cited. Also, firms with extensive technological diversity should be able to use their breadth of knowledge to generate radical innovations, even if the knowledge is sourced from within the same divisions that patent the innovations. Furthermore, technologically diverse firms may be more likely to pursue radical innovation. This implies that one needs to control for a firm's level of technological diversity when assessing the effect of internal knowledge on an invention's impact. We included a measure of technological diversity, an entropy index using the patent class of all patents filed by a firm in the five years prior to the observed patent. The entropy index was defined as $\left(-\Sigma p_{i} \times \ln \left[p_{i}\right]\right)$, where $p_{i}$ is the percentage of firm $i$ 's patents in a particular technology domain, defined by the 400 patent classes. As Argyres (1996) suggested, firms seeking radical innovation through new combinations of knowledge may reduce divisionalization to ease intrafirm knowledge sharing. Thus, we included the number of assign-

\footnotetext{
${ }^{6}$ Our measures "cite to scientific publication" and "coupling" approximate those of Fleming and Sorenson (2004). Our coupling variable mirrors their computation, using ten years of previous patents, so we do not repeat the formula here. They used a ten-year window and found effects similar to those found when they employed a window tracing all patents since 1790. We also used only ten years of data to create the measure of component familiarity. Our dummy variable for cite to scientific publication equaled 1 for all nonpatent references; however, Fleming and Sorenson (2004) reported that this rough measure behaved similarly to a more refined measure that screened for only articles in leading scientific journals.
}

ees in a firm, measured as the number of subsidiaries that applied for patents in the year of a focal patent application. ${ }^{7}$

Finally, the models also included four sets of dummy variables. First, year dummies for 198696, with 1985 as the referent, controlled for unobserved factors that vary over time but are relatively invariant across firms (e.g., economic cycles). In addition, the year dummies controlled for the tendency for newer patents to receive fewer citations than older patents. Second, industry dummies controlled for industry-specific effects. Firms were classified according to the two-digit SIC code industry in which they conducted most of their operations. We obtained these data from COMPUSTAT. Dummy variables for industries with only one firm or with less than 1 percent of the patents in the sample were omitted to aid convergence. Third, technology dummies captured differences in patenting behavior according to technology domain. For example, Hall et al. (2001) showed that citations come more quickly in some domains than others. Gaining the ability to include technology controls was a major reason we defined the sample at the patent level, rather than aggregating to the firm level. Fourth, assignee fixed effects in the fixed-effects model and an assignee random effect in the random-effects model controlled for factors that might vary substantially over patenting divisions within firms.

\section{Analysis}

For our examination, the unit of analysis was the invention. ${ }^{8}$ To assess the relationship between

\footnotetext{
7 Thanks to a reviewer for suggesting this additional control variable. Another strategy to promote intrafirm cooperation in $\mathrm{R} \& \mathrm{D}$ is to centralize research labs and R\&D spending authority (Argyres \& Silverman, 2004). For our sample, sufficient information was not available on the location of R\&D labs to include a centralization control. Survey research that measures R\&D centralization (e.g., Argyres \& Silverman, 2004) adds to understanding innovation in multibusiness firms.

${ }^{8}$ In some prior research, patents have been primarily considered indicators of inventions-new ideas that may or may not have commercial applications (e.g., Ahuja \& Lampert, 2001). However, the correlation between forward citations and economic value (e.g., Hall \& Trajtenberg, 2000) reveals that patents with a substantial impact on subsequent patenting can accurately be considered innovations-inventions that have been commercialized. We use terms such as innovativeness or impact following recent studies (Argyres \& Silverman, 2004; Gittelman \& Kogut, 2003; Rosenkopf \& Nerkar, 2001), while recogniz-
} 
search behavior and an invention's impact, we used panel data (i.e., cross-section, time series data). Each dependent variable was a nonnegative event count. The dependent variables exhibited overdispersion-the variance significantly exceeded the mean-and thus negative binomial regression was preferred over the more common Poisson model (see Hausman, Hall, and Griliches [1984] for details). However, the assumption with a negative binomial model is that event counts are independent, which was not the case here. To compensate for nonindependence, we conducted our analysis using fixed-effects and random-effects (Hausman et al., 1984) negative binomial models via the XTNBREG procedure in STATA. We only report estimates from the fixed-effects models because the random-effects models yielded almost identical estimates.

\section{RESULTS}

Table 1 displays descriptive statistics and correlations for each of the variables described in the previous section. The minimum value for the independent and dependent count variables is always 0 , and the highest count occurs for total impact, with 620 forward citations. There is substantial variance among the independent and dependent count variables. Note that for all count variables, the variances are greater than the means, indicating the presence of overdispersion. A review of the correlations among the independent variables that appear in the same model indicates that multicollinearity is generally not a cause for concern. As one might expect, the correlation of .74 between assets and technological diversity is high, but both control variables are significant in every model, and excluding either does not change any results. Also, the variable measuring the number of times cited patents had been previously cited ("times previously cited") is highly correlated (.72) with extraorganizational citations, indicating a tendency for firm members to cite well-known patents when searching outside firm boundaries, in keeping with the theory of local search. Eliminating this control variable does not affect any results.

Table 2 displays the results of the negative binomial model. In a hierarchical analysis, model 1 shows results for an unconditional model with just the assignee fixed effects; model 2 includes the control variables; and model 3 adds the covariates.

ing that, absent firms' profit motives, the theory of knowledge transfer applies primarily to the process of invention.
We used a Wald test to compare the differences in log-likelihood to a chi-square distribution using the appropriate degrees of freedom for each comparison, where the degrees of freedom correspond to the number of additional parameters in each model. Nearly all of the control variables are significantly related to the dependent variable and of similar sign and magnitude to the effects found in prior research. ${ }^{9}$ Impact, as measured by forward citations, increases with the backward citation of highly cited patents, the number of knowledge components used frequently in the near past, the breadth of a patent's reference to various subclasses, the citation of scientific publications, and the incorporation of tightly coupled knowledge components. Impact decreases with more backward citations to older patents, especially those old enough to have application dates prior to the data window ("other citations"). Also, patents from firms that are larger and more technologically diverse and that have more patenting divisions have less impact than the patents of other firms. However, even with these strong controls in place, the Wald test reveals that the covariates explained significant variance in the dependent variables, going above and beyond the random or fixed effects and control variables $\left(\chi^{2}=434, p<.001\right)$.

We predicted that researchers' use of knowledge from their own division will have a negative relationship with innovativeness. In keeping with this hypothesis, the coefficient in model 3 for intradivisional self-citations $(-0.010)$ is statistically significant $(p<.001)$ and negative. ${ }^{10}$ Next, as stated in Hypothesis 2, the coefficient for the use of extraorganizational knowledge is positive (0.006) and significant. According to Hypothesis 3, the effect of interdivisional knowledge use on impact should also be positive. Model 3 shows a significant and

\footnotetext{
${ }^{9}$ Specifically, we replicated Fleming and Sorenson's (2004) results showing that links to the underlying map of scientific knowledge and recombination of more tightly coupled components lead to greater impact. The coefficients for the interaction terms are similar to those Fleming and Sorenson reported in their model including "nonscientific" references. Note that these variables, based on the subclasses listed for a given patent, have not been included in prior research in the same models as variables based on backward citations (e.g., Rosenkopf \& Nerkar, 2001). When we did include both sets of variables, they remained significant, reinforcing confidence in the earlier results.

${ }^{10}$ A coefficient $b$ in a negative binomial model indicates that one additional unit of the independent variable relates to $b$ change in the conditional mean of the dependent variable.
} 


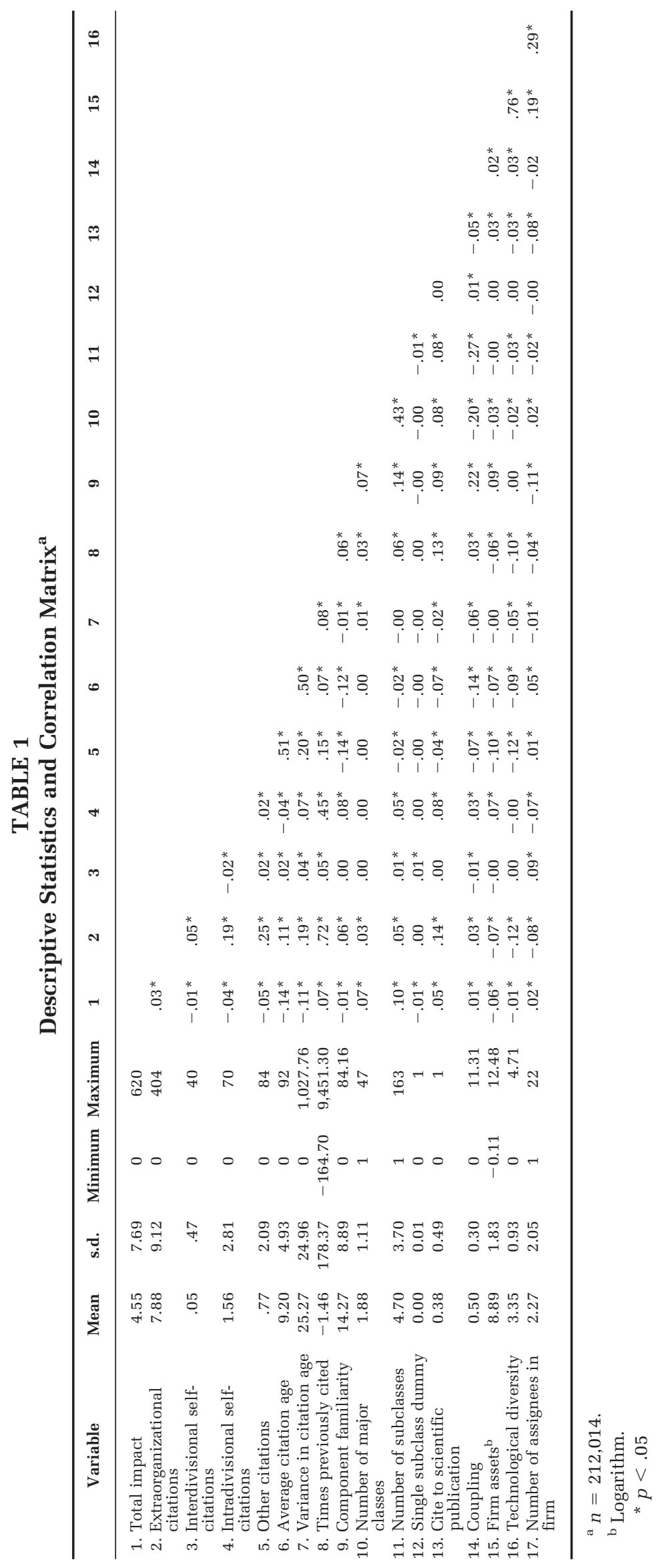


TABLE 2

Results of Negative Binomial Fixed-Effects Models Predicting Magnitude of Impact ${ }^{a}$

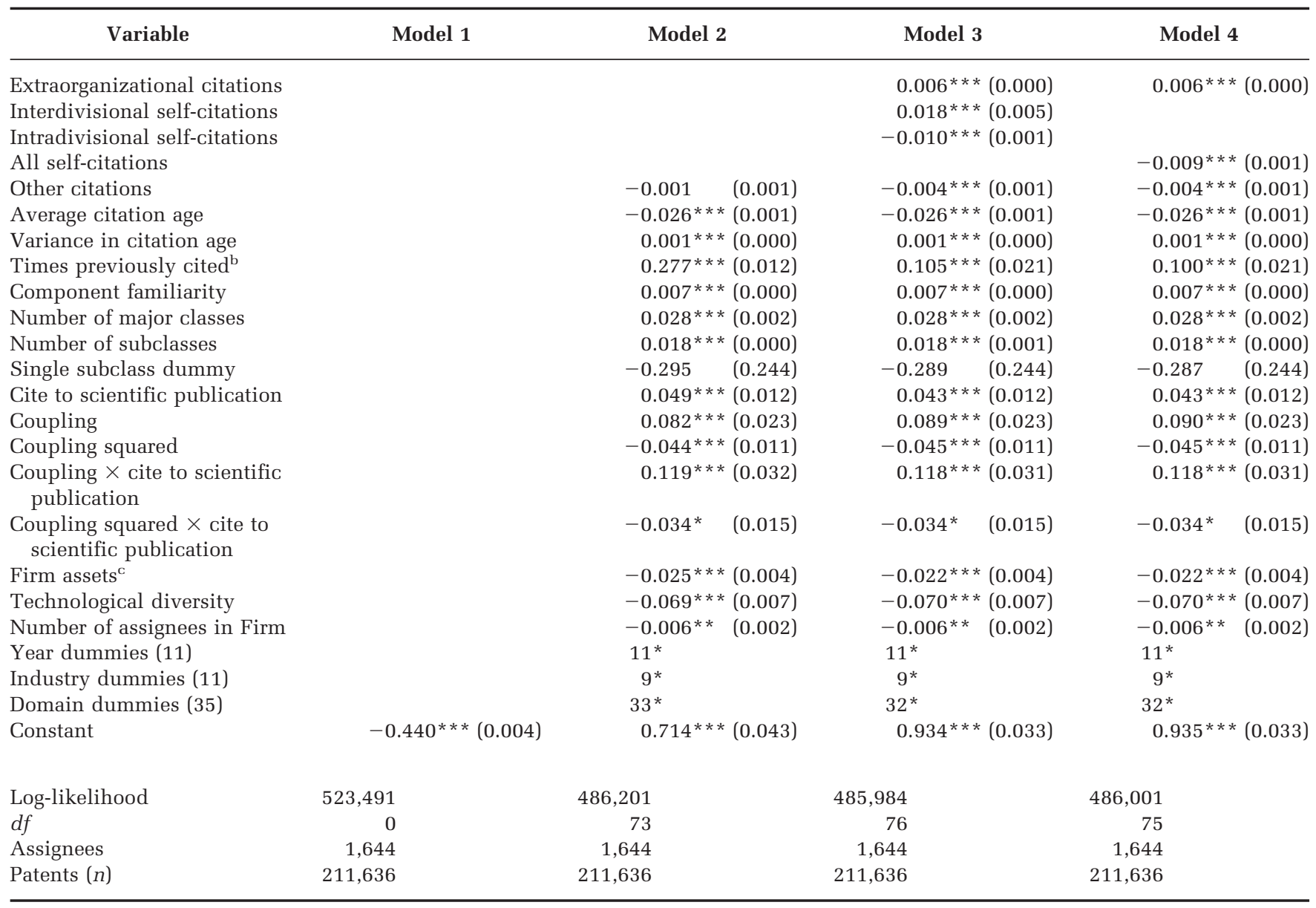

a Some observations included in the correlation table were dropped from the fixed-effects and random-effects models because the firm only had a single patent or all of its patents had a zero value for the dependent variable. Standard errors are in parentheses.

$\mathrm{b}$ The coefficient and standard error for this variable were multiplied by 1,000 for reporting in this table.

${ }^{\mathrm{c}}$ Logarithm.

${ }^{*} p<.05$

${ }^{* *} p<.01$

$* * * p<.001$

positive coefficient for interdivisional citations (0.018). Therefore, the implied null hypothesis that the use of interdivisional knowledge has no effect is rejected, and we conclude the use of interdivisional knowledge increases an invention's impact. Hypothesis 4 states further that the effect of interdivisional citations should be greater than the effect of extraorganizational or intradivisional citations. To test Hypothesis 4, we compared model 3 to a constrained version in which the coefficient for interdivisional citations was set equal to the coefficient for extraorganizational citations. A comparison of the log-likelihoods reveals that the unconstrained model is a significant improvement $\left(\chi^{2}=\right.$ 7.26, $p<.01$ ). A similar test shows that the coefficient for interdivisional citations is higher than the coefficient for intradivisonal citations $\left(\chi^{2}=32.26\right.$, $p<.001$ ). The use of interdivisional knowledge has a more positive effect on magnitude of impact than does the use of extraorganizational or intradivisional knowledge, as hypothesized.

\section{DISCUSSION}

We began this paper by discussing the potential problems associated with local and distant exploration. Focus on a given expertise underpins the development of core capabilities, yet failure to explore beyond existing techniques leads to a decayed competitive stance. However, distant exploration, which underlies the ability to change and adapt, is difficult to undertake because knowledge is not amenable to transfer over organizational boundaries. We have presented the sourcing of dis- 
tant knowledge from disparate divisions in a diversified firm as an alternative. Supporting our predictions, the use of knowledge from distinct divisions had a significant, positive relationship with an invention's impact on the subsequent evolution of technology. Although the effect of knowledge from within the same division as the division forwarding an invention was consistently negative, firms with multiple divisions can overcome many of these problems of local search by transferring knowledge between divisions. Furthermore, as predicted, we found that the overall effect of interdivisional knowledge use was even greater than the effect of using knowledge from outside the boundaries of a firm. The inclusion of various control variables and model specifications increased confidence in the results. If one considers that the use of interdivisional knowledge may also be less costly and less risky, and have fewer unintended consequences (such as information leaked in the other direction) than the use of extraorganizational knowledge, the value of interdivisional knowledge sharing is even greater than what is revealed in these empirical results.

We include model 4 in Table 2 to emphasize the importance of recognizing divisional boundaries in research on knowledge flows. If all the references to previous patents from a single parent company (all self-citations) were grouped, it would appear that the use of extraorganizational knowledge is superior to intraorganizational knowledge use $(0.006>$ $-0.009 ; p<.0001)$. Yet the use of interdivisional knowledge is actually superior to the use of intradivisional knowledge or extraorganizational knowledge. Thus, a key advantage of multidivisional firms is that they facilitate the diffusion of information impacted in a particular group over a boundary to another group. Internalizing a boundary within a firm reduces opportunism and enhances systems of communication relative to interfirm boundaries. Therefore, the vertical and horizontal scope of a firm depends not only on the characteristics of the current transactions between parties, but also on the ongoing potential for cross-fertilization of knowledge to promote innovation (Chang, 1996; Miller, 2004).

\section{Comparison to Prior Research}

Our findings confirmed that the use of interdivisional knowledge is effective in innovation activities. However, prior research suggests ways to further divide the data to check for robustness of the results. Specifically, Rosenkopf and Nerkar (2001) defined "domain impact" as the number of citations a focal patent received from other patents in any patent class applying to optical disc drive technology (their research context). As the distance between technologies in three-digit patent classes is often negligible, we employed a higher-level categorization scheme (Hall et al., 2001) that aggregated the 400 three-digit classes into 36 two-digit subcategories used to represent technological domains. ${ }^{11}$ We refer to the count of forward citations from patents in the same subcategory as "domain impact" and to the count of citations from all other patents as "nondomain impact." Adding domain and nondomain citations yields a measure of "total" impact. ${ }^{12}$ Further, Rosenkopf and Nerkar (2001) did not simply compare intraorganizational to extraorganizational citations but hypothesized about the relative effect of knowledge sourced from within or beyond firm boundaries in combination with the technological boundaries being crossed. In Table 3, we report further analysis using these distinctions. Rosenkopf and Nerkar (2001) also conducted their research at the firm level, adding backward and forward citations for all patents held by the same firm in the same time period. We chose to examine the use of interdivisional knowledge using data at the patent level so we could include control variables that corresponded to the technological domains of the patents, given our desire to include diversified firms in the sample. However, our patent-level results generally replicate those from prior research at the firm level of analysis.

Models 1 through 3 of Table 3 use Rosenkopf and Nerkar's (2001) independent variables. For domain impact, extraorganizational exploration within a given technology domain has the highest positive coefficient, and self-citations outside the technology domain have the most negative effect. Also in line with Rosenkopf and Nerkar's (2001) research, self-citations within the technological domain have the most negative nondomain (and total) impact, and extraorganizational cites beyond the domain have a positive nondomain (and total) impact. However, we find that self-citations beyond the domain have a strong, positive effect on nondomain impact, whereas prior research has reported an insignificant effect on total impact. The differences likely stem from our sample firms representing more industries, our sample size generating greater

\footnotetext{
${ }^{11}$ An alternative specification using the 400 technical classes to define the domains yielded results the same as those in the tables. Using the 400 classes prevented us from including technology dummies in the model, given the size of the data matrix.

${ }^{12}$ The measure we call "nondomain impact" is what Rosenkopf and Nerkar (2001) termed "overall impact."
} 


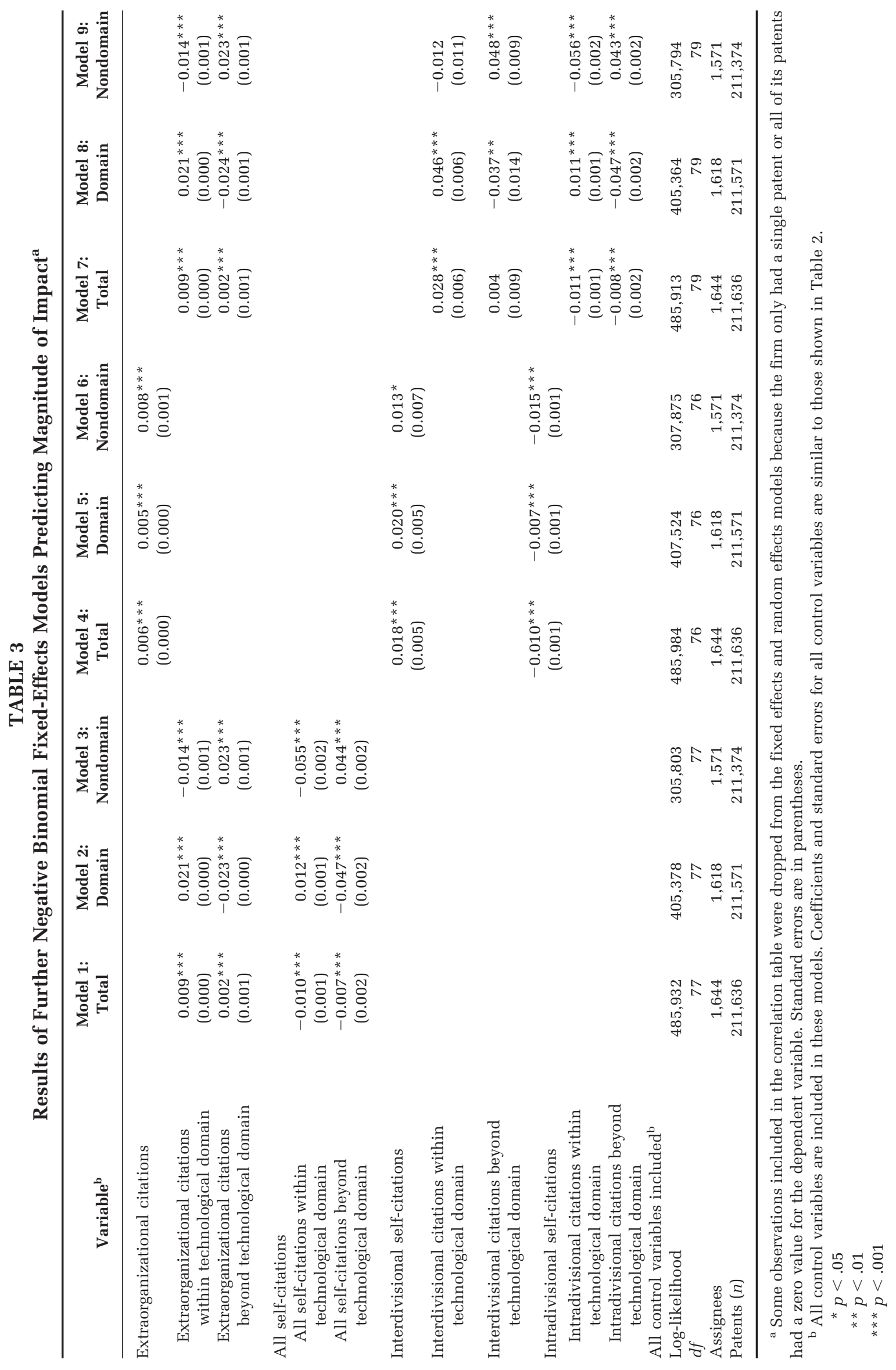


power, and our measures of technological domains being broader.

Models 4 through 6 report the results using our independent variables, including the interdivisional citations, and models 7 through 9 separate the backward citations according to both divisional and technological boundaries. The effects of intradivisional, extraorganizational, and interdivisional knowledge use are consistent with earlier results (model 4: total impact) whether using domain or nondomain impact (models 5 and 6). The most consistent pattern in models 7 through 9 is that the coefficient for interdivisional citations within the technological domain of a focal patent is significantly more strongly positive than the coefficient for intradivisional citations within the technological domain; for example, in model $7,0.028$ is significantly higher than $-0.011\left(\chi^{2}=32.72, p<\right.$ $.01)$. However, moving to the six independent variables in these last models begins to cut the data rather fine. There are only 2,246 instances of interdivisional citations from beyond the domain in the entire sample, making it difficult to find statistical significance. ${ }^{13}$ Nevertheless, the effect sizes indicate that interdivisional knowledge from within a focal domain appears to be more effectively, as well as more frequently, used than interdivisional knowledge from outside the domain. Among other results, model 9 shows that using knowledge from other domains that will provide the basis for nondomain impact is the one time when intradivisional knowledge use is superior to extraorganizational knowledge use $(0.043>0.023 ; p<.001)$. Thus, there are times when local knowledge is more valuable than distant knowledge; the problem with local search is that inventors often use local knowledge too frequently.

\footnotetext{
${ }^{13}$ For example, the coefficient for interdivisional citations (0.20) is significantly higher than the coefficient for extraorganizational citations (0.005) in model 5 , but in model 6, the relevant coefficients are not significantly different. These results imply the search and transfer of knowledge from other divisions has the greatest impact on future research within a single technological domain. However, citations from beyond the technological domain are most important for nondomain impact. Since there are few of these in the sample for interdivisional citations, we do not have the statistical power to draw conclusions about comparative effects on domain or nondomain impact. In practice, however, it appears firms tend to acquire companies or engage in corporate entrepreneurship mainly to expand their knowledge within a domain.
}

\section{Robustness Check}

To gain a finer-grained measure of the knowledge being used from prior patents, we distinguished the first backward citation by an assignee to any particular patent and then reran the analysis as discussed above. We conjectured that the first use of a specific patent likely represents a greater degree of knowledge use than do subsequent citations of that same patent. For instance, subsequent citations of the same patent over time may simply result from the routinized behavior of the inventor. We find that first-use citations have a more strongly positive effect on impact whether they refer to intradivisional, interdivisional, or extraorganizational patents. However, the relative effects of intradivisional, interdivisional, and extraorganizational knowledge use are just as reported in the main models: interdivisional citations have the most strongly positive impact. Likewise, the results regarding citations from within and beyond the technological domain are unchanged when one makes the first-use distinction.

\section{Limitations and Future Research}

Patent citations and knowledge flows. Patenting is a coarse measure of the knowledge firms possess and maintain, and citations are not an exhaustive measure of knowledge flows. Citation can mean something other than the use of knowledge from a prior patent. Our numerous control variables were meant to account for many of the factors that affect whether a patent gets cited. Further research is needed on the incentives and search routines of inventors and other participants in the patent process.

One factor that we could not control for in our study was whether a patent lawyer or examiner, rather than the inventor, included a particular citation in a patent application. The U.S. Patent and Trademark Office has only provided an indicator of examiner-added citations in patent applications since 2001. If anything, however, we expect that examiners introduce common citations to many patents, seeking to link new inventions to seminal inventions in the same class, and that class dummies would partially control for this. According to past research, examiners seem to add citations that come from various sources-the same division, other divisions in the same firm, and other firms-in the same proportion as inventors cite from each source (Alcacer \& Gittelman, 2006). Therefore, the examiner citations should be adding similar noise to each type. On the other hand, examiners are more likely than inventors to add cita- 
tions within the same patent class. Thus, there is potentially more noise in the citations within a technological domain. Of course, we were not testing for the occurrence of local search, but for its effects. Adjusting for examiner citations would require an explanation of whether backward citations added by an inventor versus an examiner are more likely to lead to more forward citations, and why. With our large sample, the significance levels are so strong that adjusting the standard errors to account for this noise would almost certainly not change the results.

In sum, even if citations are a somewhat noisy indicator of this phenomenon, we remain confident that the patent application process reveals substantial information about knowledge search and transfer (Jaffe et al., 2000). Thus, we are confident in our results.

Divisional and geographic boundaries. This study examined only two dimensions of distance in knowledge: technological domains and organizational boundaries. It is not clear how much of the effect of divisional boundaries was also related to firms operating over geographic distance. The front page of a patent contains the full address for the inventor and assignee, although most patent databases report geographic data at only the state or country level. Our exploratory research (not reported in a table) showed a high correlation between divisional boundaries within the diversified firms and the locations of the inventors by state in our sample: divisions that file patents separately from their parent organization tend to be geographically distant from other divisions in the same firm. However, as scholars attempt to incorporate multiple dimensions of knowledge distance into a single study, divisional boundaries need to be considered to have a full view of the effects of a firm using its existing knowledge.

Divisions and acquisitions. This study should be interpreted as a close complement to research on acquisitions as a means to facilitate knowledge transfer. Given the large sample size, we did not identify which divisions were added to firms through acquisition, although most probably were. Empirical research has studied mostly horizontal acquisitions in high-technology industries (e.g., Ahuja \& Katila, 2001; Capron et al., 1998; Karim \& Mitchell, 2000). An acquiring firm gains control of its target firm's employees and routines and thus its tacit knowledge, but at the risk of alienating employees (Jemison \& Sitkin, 1986) or overpaying for the target firm (Chi, 1994; Coff, 1999). We examined the ongoing effect of having acquired knowledge through acquisition. If there is substantial knowledge-based synergy between divisions, its ef- fect should be observable over time, and it is. Also, our finding that most interdivisional citations were within single domains is consistent with the literature's emphasis on horizontal acquisitions. However, as noted in the quotation at the beginning of this paper, the use of interdivisional knowledge is not restricted to divisions that might be considered "related" in terms of their product-markets or SIC codes. Distant search across "unrelated" divisions might be rare, but also less imitable, and thus a possible source of sustainable competitive advantage.

Impact and firm performance. Finally, we have not linked our dependent variable to product-market or firm financial performance. Despite 30 years of research, there is still extensive debate concerning the relationship between corporate diversification and performance (Palich et al., 2000). In general, related diversification is superior to unrelated diversification as a route to achieving performance advantages. However, our results suggest that firms pursuing seemingly unrelated diversification (e.g., General Electric, Virgin Atlantic) might also accrue some advantage by sharing knowledge across units, especially if they can gain the same innovation benefits for less cost than they would incur if they transferred knowledge from outside. A corporation that pursues a strategy of unrelated diversification but ensures that technologies have combinatory potential over divisions could enhance its financial synergy with some operational synergy, at least in product development. Although financial economies are realized only if units are allowed to operate relatively autonomously, as Hill and Hoskisson noted, "If [operational] synergy is based upon shared R\&D knowledge, then small coordinating units may achieve this with only minimal interference in divisional authority" (1987: 335). Further research linking the use of different types of knowledge to firm financial performance could estimate the benefits of such hybrid diversification strategies.

\section{REFERENCES}

Abernathy, W. J., \& Utterback, J. M. 1978. Patterns of industrial innovation. Technology Review, JuneJuly: 41-47.

Ahuja, G., \& Katila, R. 2001. Technological acquisitions and the innovation performance of acquiring firms: A longitudinal study. Strategic Management Journal, 22: 197-220.

Albert, M. B., Avery, D., Narin, F., \& McAllister, P. 1991. Direct validation of citation counts as indicators of industrially important patents. Research Policy, 20(3): 251-259. 
Alcacer, J., \& Gittelman, M. 2006. Patent citations as a measure of knowledge flows: The influence of examiner citations. Review of Economics and Statistics, 88: $774-779$.

Almeida, P., \& Kogut, B. 1999. The localization of knowledge and the mobility of engineers in regional networks. Management Science, 45: 905-917.

Argote, L., \& Ingram, P. 2000. Knowledge transfer: A basis for competitive advantage in firms. Organizational Behavior and Human Decision Processes, 82: 150-169.

Argyres, N. S. 1996. Capabilities, technological diversification and divisionalization. Strategic Management Journal, 17: 395-410.

Argyres, N. S., \& Silverman, B. S. 2004. R\&D, organization structure, and the development of corporate technological knowledge. Strategic Management Journal, 25: 929-958.

Arrow, K. 1962. Economic welfare and the allocation of resources for inventions. In $\mathrm{R}$. Nelson (Ed.), The rate and direction of inventive activity: 609-625. Princeton, NJ: Princeton University Press.

Barney, J. 1991. Firm resources and sustained competitive advantage. Journal of Management, 17(1): 99120.

Brown, S., \& Eisenhardt, K. M. 1995. Product development: Past research, present findings, and future directions. Academy of Management Journal, 20: 343-378.

Brusoni, S., Prencipe, A., \& Pavitt, K. 2001. Knowledge specialization, organizational coupling, and the boundaries of the firm: Why do firms know more than they make? Administrative Science Quarterly, 46: 597-621.

Capron, L., Dussauge, P., \& Mitchell, W. 1998. Resource redeployment following horizontal acquisitions in Europe and North America, 1988-1992. Strategic Management Journal, 19: 631-661.

Cardinal, L. B., \& Hatfield, D. E. 2000. Internal knowledge generation: The research laboratory and innovative productivity in the pharmaceutical industry. Journal of Engineering and Technology Management, 17: 247-271.

Cardinal, L. B., \& Opler, T. C. 1995. Corporate diversification and innovative efficiency: An empirical study. Journal of Accounting and Economics, 19: 365-381.

Chang, S. J. 1996. An evolutionary perspective on diversification and corporate restructuring: Entry, exit, and economic performance during 1981-89. Strategic Management Journal, 17: 587-611.

Chi, T. 1994. Trading in strategic resources: Necessary conditions, transaction cost problems, and choice of exchange structure. Strategic Management Journal, 15: 271-290.

Coff, R. W. 1999. How buyers cope with uncertainty when acquiring firms in knowledge-intensive industries: Caveat emptor. Organization Science, 10: $144-161$.

Cohen, W. M., \& Levinthal, D. A. 1990. Absorptive capacity: A new perspective on learning and innovation. Administrative Science Quarterly, 35: 128152 .

Daft, R., \& Lengel, R. 1986. Organizational information requirements, media richness and structural design. Management Science, 32: 554-571.

Fern, M. J., \& Cardinal, L. B. 2003. From corporate strategy to performance: The effect of interunit knowledge transfer on innovativeness. Academy of Management Proceedings, D1-D6.

Fleming, L. 2001. Recombinant uncertainty in technological search. Management Science, 47: 117-132.

Fleming, L., \& Sorenson, O. 2004. Science as a map in technological search. Strategic Management Journal, 25: 909-928.

Galunic, D. C., \& Rodan, S. 1998. Resource recombinations in the firm: Knowledge structures and the potential for Schumpeterian innovation. Strategic Management Journal, 19: 1193-1201.

Gavetti, G., \& Levinthal, D. 2000. Looking forward and looking backward: Cognitive and experiential search. Administrative Science Quarterly, 45: 113137.

Gittelman, M., \& Kogut, B. 2003. Does good science lead to valuable knowledge? Biotechnology firms and the evolutionary logic of citation patterns. Management Science, 49: 366-382.

Grant, R. 1996. Toward a knowledge-based theory of the firm. Strategic Management Journal, 17(winter special issue): 109-122.

Gupta, A. K., \& Govindarajan, V. 2000. Knowledge flows within multinational corporations. Strategic Management Journal, 21: 473-496.

Hall, B. H., Jaffe, A. B., \& Trajtenberg, M. 2001. The NBER patent citations data file: Lessons, insights and methodological tools. NBER working paper no. 8498. Cambridge, MA: National Bureau of Economic Research.

Hall, B. H., \& Trajtenberg, M. 2000. Market value and patent citations: $\boldsymbol{A}$ first look. NBER working paper \#7741. Cambridge, MA: National Bureau of Economic Research.

Hamel, G. 1991. Competition for competence and interpartner learning within international strategic alliances. Strategic Management Journal, 12: 83-103.

Hansen, M. T. 2002. Knowledge networks: Explaining effective knowledge sharing in multiunit companies. Organization Science, 13: 232-248.

Harfhoff, D., Narin, F., Scherer, F. M., \& Vopel, K. 1999. Citation frequency and the value of patented inven- 
tions. Review of Economics and Statistics, 81: 511515.

Hausman, J., Hall, B. H., \& Griliches, Z. 1984. Econometric-models for count data with an application to the patents-R and D relationship. Econometrica, 52: 909-938.

Henderson, R. M., \& Clark, K. B. 1990. Architectural innovation: The reconfiguration of existing product technologies and the failure of established firms. Administrative Science Quarterly, 35: 9-30.

Henderson, R. M., \& Cockburn, I. 1994. Measuring competence? Exploring firm effects in pharmaceutical research. Strategic Management Journal, 15: 6384.

Henderson, R. M., Jaffe, A., \& Trajtenberg, A. 1998. Universities as a source of commercial technology: A detailed analysis of university patenting, 1965-1988. Review of Economics and Statistics, 80: 119-127.

Hill, C. W. L., \& Hoskisson, R. E. 1987. Strategy and structure in the multiproduct firm. Academy of Management Review, 12: 331-341.

Hitt, M. A., Hoskisson, R. E., Ireland, R. D., \& Harrison, J. S. 1991. Effects of acquisitions on R\&D inputs and outputs. Academy of Management Journal, 34: 693-706.

Jaffe, A. B., Trajtenberg, M., \& Fogarty, M. S. 2000. The meaning of patent citations: Report on the NBER/ Case Western Reserve Survey of Patentees. NBER Working Paper no. 7631. Cambridge, MA: National Bureau of Economic Research.

Jemison, D. B., \& Sitkin, S. B. 1986. Corporate acquisitions: A process perspective. Academy of Management Review, 11: 145-163.

Karim, S., \& Mitchell, W. 2000. Path-dependent and path-breaking change: Reconfiguring business resources following acquisitions in the US medical sector, 1978-1995. Strategic Management Journal, 21: 1061-1081.

Kogut, B., \& Zander, B. 1992. Knowledge of the firm, combinative capabilities, and the replication of technology. Organization Science, 3: 383-397.

Leonard-Barton, D. 1992. Core capabilities and core rigidities: A paradox in managing new product development. Strategic Management Journal, 13: 111125.

Liebeskind, J. P. 1996. Knowledge, strategy, and the theory of the firm. Strategic Management Journal, 17(special issue): 93-108.

Liebeskind, J. P., Oliver, A. L., Zucker, L., \& Brewer, M. 1996. Social networks, learning, and flexibility: Sourcing scientific knowledge in new biotechnology firms. Organization Science, 7: 428-443.

Leiblein, M. J., \& Miller, D. J. 2003. An empirical examination of transaction- and firm-level influences on the vertical boundaries of the firm. Strategic Management Journal, 24: 839-859.
March, J. G. 1991. Exploration and exploitation in organizational learning. Organization Science, 2: 71-87.

March, J. G., \& Simon, H. 1958. Organizations. New York: Wiley.

Markides, C. C., \& Williamson, P. J. 1994. Related diversification, core competences and corporate performance. Strategic Management Journal, 15: 149165.

Miller, D. J. 2004. Firms' technological resources and the performance effects of diversification: A longitudinal study. Strategic Management Journal, 25: 1097-1119.

Mota, J., \& de Castro, L. M. 2004. A capabilities perspective on the evolution of firm boundaries: A comparative case example from Portuguese moulds industry. Journal of Management Studies, 41: 295-316.

Mowery, D. C., Oxley, J. E., \& Silverman, B. S. 1996. Strategic alliances and interfirm knowledge transfer. Strategic Management Journal, 17: 77-91.

Nagarajan, A., \& Mitchell, W. 1998. Evolutionary diffusion: Internal and external methods used to acquire encompassing, complementary, and incremental technological changes in the lithotripsy industry. Strategic Management Journal, 19: 1063-1077.

Nayyar, P. R., \& Kazanjian, R. K. 1993. Organizing to obtain potential benefits from information asymmetries and economies of scope in related diversified firms. Academy of Management Review, 18: 735759.

Nelson, R. R., \& Winter, S. G. 1982. An evolutionary theory of economic change. Cambridge, MA: Belknap.

Nerkar, A., \& Roberts, P. W. 2004. Technological and product-market experience and the success of new product introductions in the pharmaceutical industry. Strategic Management Journal, 25: 779-799.

Nickerson, J. A., \& Zenger, T. R. 2004. A knowledgebased theory of the firm-The problem-solving perspective. Organization Science, 15: 617-632.

Palich, L. E., Cardinal, L. B., \& Miller, C. C. 2000. Curvilinearity in the diversification-performance linkage: An examination of over three decades of research. Strategic Management Journal, 21: 155-174.

Pavitt, K., Robson, M., \& Townsend, J. 1989. Technological accumulation, diversification, and organisation in U.K. companies, 1945-1983. Management Science, 35: 81-99.

Pisano, G. P. 1990. The research-and-development boundaries of the firm: An empirical analysis. Administrative Science Quarterly, 35: 153-176.

Polanyi, M., \& Walshe, F. 1966. The tacit dimension. Garden City, NY: Doubleday.

Robins, J. A., \& Wiersema, M. 1995. A resource-based approach to the multibusiness firm. Strategic Management Journal, 16: 277-299. 
Rosenkopf, L., \& Almeida, P. 2003. Overcoming local search through alliances and mobility. Management Science, 49: 751-766.

Rosenkopf, L., \& Nerkar, A. 2001. Beyond local search: Boundary-spanning exploration, and impact in the optical disk industry. Strategic Management Journal, 22: 287-306.

Santos, F. M., \& Eisenhardt, K. M. 2005. Organizational boundaries and theories of organization. Organization Science, 16: 491-508.

Schumpeter, J. A. 1947. The creative response in economic history. Journal of Economic History, 7: 149159.

Simon, H. A. 1962. The architecture of complexity. Proceedings of the American Philosophical Society, 106: 467-482.

Song, J., Almeida, P., \& Wu, G. 2003. Learning-by-hiring: When is mobility more likely to facilitate interfirm knowledge transfer? Management Science, 49: 351365.

Stuart, T. E., \& Podolny, J. M. 1996. Local search and the evolution of technological capabilities. Strategic Management Journal, 17: 21-38.

Szulanski, G. 1996. Exploring internal stickiness: Impediments to the transfer of best practice within the firm. Strategic Management Journal, 17(winter special issue): 27-43.

Takeishi, A. 2001. Bridging inter- and intra-firm boundaries: Management of supplier involvement in automobile product development. Strategic Management Journal, 22: 403-433.

Teece, D. J. 1980. Economies of scope and the scope of the enterprise. Journal of Economic Behavior \& Organization, 1: 223-247.

Teece, D. J. 1986. Profiting from technological innovation: Implications for integration, collaboration, licensing and public policy. Research Policy, 15: 285-305.

Thompson, P., \& Fox-Kean, M. 2005. Patent citations and the geography of knowledge spillovers: A reassessment. American Economic Review, 95: 450-460.

Tijssen, R. 2001. Global and domestic utilization of industrial relevant science: Patent citation analysis of science-technology interactions and knowledge flows. Research Policy, 30: 35-54.

Trajtenberg, M. 1990. A penny for your quotes: Patent citations and the value of innovations. Rand Journal of Economics, 21: 172-187.

Tsai, W. 2001. Knowledge transfer in intraorganizational networks: Effects of network position and absorptive capacity on business unit innovation and perfor- mance. Academy of Management Journal, 44: 9961004.

Tushman, M. L. 1977. Special boundary roles in the innovation process. Administrative Science Quarterly, 22: 587-605.

Tushman, M. L., \& Anderson, P. 1986. Technological discontinuities and organizational environments. Administrative Science Quarterly, 31: 439-465.

von Hippel, E. 1994. Sticky information and the locus of problem-solving: Implications for innovation. Management Science, 40: 429-439.

Walsh, J. P. 1995. Managerial and organizational cognition: Notes from a trip down memory lane. Organization Science, 6: 280-321.

Williamson, O. E. 1975. Markets and hierarchies: Analysis and antitrust implications. New York: Free Press.

Williamson, O. E. 1981. The economics of organization: The transaction cost approach. American Journal of Sociology, 87: 548-577.

Williamson, O. E. 1985. The economic institutions of capitalism. New York: Free Press.

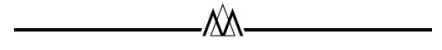

Douglas J. Miller (djmiller@uiuc.edu) is an assistant professor in the Department of Business Administration at the University of Illinois at Urbana-Champaign. His research in corporate strategy focuses on vertical integration, diversification, and merger and acquisition decisions under conditions of competitive heterogeneity in technological resources. He received his Ph.D. from The Ohio State University.

Michael J. Fern (mfern@uvic.ca) is an assistant professor of entrepreneurship and innovation in the Faculty of Business and the executive director of The Utilium Network at the University of Victoria. His research focuses on the creation, use, and transfer of knowledge in the contexts of entrepreneurship and innovation. He received his Ph.D. from the University of North Carolina at Chapel Hill.

Laura B. Cardinal (cardinal@tulane.edu) is an associate professor and the Exxon Professor of Strategy at the A. B. Freeman School of Business, Tulane University. Her research interests center on managing innovation and change, specifically focusing on managing new product development capabilities, the management and location of R\&D in diversified firms, and managing control system adaptation. She received her Ph.D. from the University of Texas at Austin.

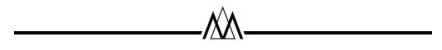


Copyright of Academy of Management Journal is the property of Academy of Management and its content may not be copied or emailed to multiple sites or posted to a listserv without the copyright holder's express written permission. However, users may print, download, or email articles for individual use. 